\title{
Analysis on the voltage stability on transmission network with PV interconnection
}

\author{
Karmila Kamil, Muhammad Amirul Ashraf Ab Rahman, Chong Kok Hen, Halimatun Hashim, Mohd \\ Helmi Mansor \\ Department of Electrical and Electronics Engineering, College of Engineering, Universiti Tenaga Nasional, Malaysia
}

\begin{tabular}{|c|c|}
\hline Article Info & ABSTRACT \\
\hline Article history: & stability means the ability of the power system network to maintain \\
\hline Received Apr 30, 2019 & $\begin{array}{l}\text { steady-state voltage value at all buses in the system under normal condition } \\
\text { and after being subjected to a disturbance. This research highlights the effect }\end{array}$ \\
\hline Revised Jun 20, 2019 & of solar photovoltaic (PV) as the subject of disturbance to the network \\
\hline Accepted Jul 10, 2019 & $\begin{array}{l}\text { system as this kind of energy source has emerged towards higher level of } \\
\text { integration into the national grid. High penetration of solar PV into the grid }\end{array}$ \\
\hline Keywords: & $\begin{array}{l}\text { may cause several issues of stability and security to the system particularly } \\
\text { effecting the normal voltage and line overloading. This research is focused }\end{array}$ \\
\hline Lin & on the simulation of power flow to study the transmission network behavior \\
\hline Power flow & with and without the solar PV interconnection. To accomplish the research \\
\hline Solar PV penetration & $\begin{array}{l}\text { objectives, the network system will be modelled in a software known as } \\
\text { Power System Simulator for Engineering (PSSE). The simulation result will }\end{array}$ \\
\hline Voltage stability & be discussed and analyzed using Voltage Stability Indices (VSI) to prove and \\
\hline Voltage Stability Indices (VSI) & trengthen the theory behind the literature review. \\
\hline
\end{tabular}

Copyright $\odot 2019$ Institute of Advanced Engineering and Science. All rights reserved.

\section{Corresponding Author:}

Karmila Kamil,

Department of Electrical and Electronics Engineering,

College of Engineering, Universiti Tenaga Nasional,

Jalan Ikram-Uniten, 43000 Kajang, Selangor, Malaysia.

Email: karmila@uniten.edu.my

\section{INTRODUCTION}

Solar energy is currently one of the most growing and reliable energy source all over the world as this type of energy is the most abundant, clean and eco-friendly of all the renewable energy resources. PV technology is one of the finest ways to harness this solar power. Photovoltaic device acts as stand-alone system that enables direct conversion of sunlight into electricity outputs ranging from microwatts to megawatts [1]. The solar PV usually being set to operate at unity power factor which means that it only injecting active power (MW) output to the network system.

Nowadays, many nations in the world has connected PV solar system to their respective power grid as one of the electricity sources due to energy demands keep increasing [2]. For example, China has been the largest photovoltaic generation installed capacity in the world. As for 2015, China has generate approximately $392 \mathrm{GWh}$ of power from photovoltaic system annually [3]. According to ERU Annual Report on the Operation of the Energy System in Republic Czech in 2015, photovoltaic has produced 2263.8 GWh which is $10 \%$ of installed capacity share for the country [4]. Meanwhile, $7.236 \mathrm{GWh}$ of total solar energy produced in Romania in 2016 [5].

Despite of all the advantages and benefits of the usage of photovoltaic interconnection with national power grid, there's some potential side issue that need to be concern by every nation. Solar energy were classified as one of the non-dispatchable renewable energy. Non-dispatchable means that the input power or energy harvested from the Sun cannot be controlled [6]. 
One of the main concern regarding the usage of solar PV is the ability to dispatch desired power output according to demand. This is because there will be a time where the total power generated exceeding the total load demand or in other word the net power is not equilibrium. Under normal operating condition, there are many option for scheduling power generation. In a typical power system, the objective is to determine the active and reactive power scheduling of each power plant. This indicates that the generator's active and reactive power are enabled to vary within certain limits in order to meet a particular load demand [7].

Besides, the electrical energy generated from solar PV are differ from conventional generators in term of moment of inertia. Inertia is induced from fundamental mechanical equipment in the generator which results in producing reactive power to the power system. The reactive power supply is related to the dynamic performance of the system in order to maintain the system transient stability while avoiding disturbance in the power system. Therefore, solar PV penetration which is replacing conventional generator will reducing inertia within the system while limiting the magnitude of reactive power supplied into the system [8,9]. Reactive power plays an important role in a power system as it affects voltages throughout the network system [10].

Based on [11-14], voltage stability refers to the ability of the power system to maintain acceptable voltage value at all buses in the system under normal condition and after being subjected to a disturbance. Every power system are designed to operate and well-function within a range of voltages. According to TNB Grid Code, the steady-state voltage level under normal condition for $132 \mathrm{kV}$ network system is within the range of $-5 \% \&+10 \%$ [15]. Any violation in term of stated limit is considered as voltage collapse and causes system instability issues. With the presence of solar PV, the normal limit of power generation will be affected and causing some instability and reliability issues to the network system. This will trigger some concern towards the normal voltage of the bus system.

This paper investigates the impact of solar PV into a transmission network mainly towards the voltage stability of the whole network. The paper is summarized accordingly: Section I provides the research background and introduction. Section II and III will describing the detailed methodology and test systems while Section IV illustrating the results. Section V will conclude all the key findings of this research. Section VI is s list of references used to support information for this paper work.

\section{RESEARCH METHOD}

\subsection{Voltage stability indices}

Voltage stability analysis can be evaluated by the VSI referred to a line in the power system network. VSI are important in deciding the limit of the operating point to voltage collapse point. VSI were used to detect the most sensitive line or bus in the network system. Generally, the index value varies in between 0 and 1 . In order to maintain stable-state condition, the index value must be less than value 1 . Voltage collapse occurred when the index showing value beyond 1 . This research also proposes the suitable location PV placement in the simulation network based on a VSI calculation which is to determine the weakest bus in the system [16-17]. These VSI are derived directly from a single line diagram as shown in Figure 1 [18-22].

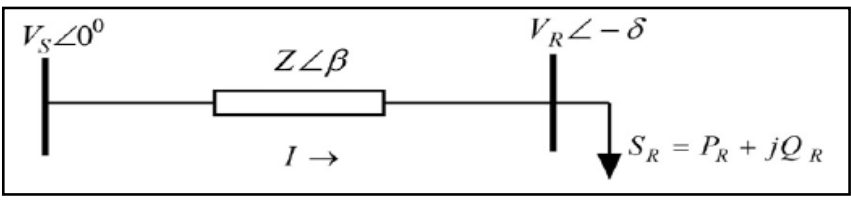

Figure 1. Single line 2 bus system

Where: $V_{S}=$ Voltage of sending bus

$\mathrm{V}_{\mathrm{R}}=$ Voltage of receiving bus

$\delta=$ Angle of voltage

$\mathrm{Z}=$ Line impedance

$\beta=$ Angle of line impedance

$\mathrm{S}_{\mathrm{R}}=$ Apparent power of receiving bus

$\mathrm{P}_{\mathrm{R}}=$ Active power of receiving bus

$\mathrm{Q}_{\mathrm{R}}=$ Reactive power of receiving bus 
For this research, there are 3 types of induces that have been used:

a. Fast voltage stability index (FVSI)

$$
F V S I=\frac{4 Z^{2} Q_{R}}{V_{S}^{2} X}
$$

b. Line stability factor (LQP)

$$
L Q P=\frac{4 X}{V_{S}^{2}}\left[\frac{X P_{S}^{2}}{V_{S}^{2}}+Q_{R}\right]
$$

c. Line voltage stability index (LVSI)

$$
L V S I=\frac{4 X P_{R}}{\left[V_{S} \cos (\theta-\delta)\right]^{2}}
$$

\subsection{Proposed approaches and method}

The overall procedures in order to achieve the objectives of this research divided into two parts:

a. The procedure to find the suitable placement of the solar PV source is described as:

Step 1: Load base case bus test system data in PSSE software.

Step 2: Simulate the power flow of the network and obtain the voltage.

Step 3: Calculate the VSI using (1), (2) and (3).

Step 4: Determine the weakest bus using the VSI.

b. The procedure to determine the maximum output for the solar PV is describe as belows:

Step 5: PV is injected into the bus system at the weakest bus

Step 6: Initially, the output of the solar PV started with $100 \mathrm{MW}$.

Step 7: Repeat Step 2 and 3

Step 8: Increase the PV output by $100 \mathrm{MW}$ for every test until the system collapsed and there is violation in bus voltage magnitude.

\section{TEST SYSTEM}

In order to test and verify the proposed approach, the network model is based on the 14 bus test system. All the bus, line and generator data for the system is provided from IEEE. The 14 bus network consists of 5 generator buses, 11 load buses and 20 lines. The base voltage considered to be $132 \mathrm{kV}$ for transmission network with 100 MVA for base MVA. Figure 2 shows the single line diagram for IEEE 14 bus system.

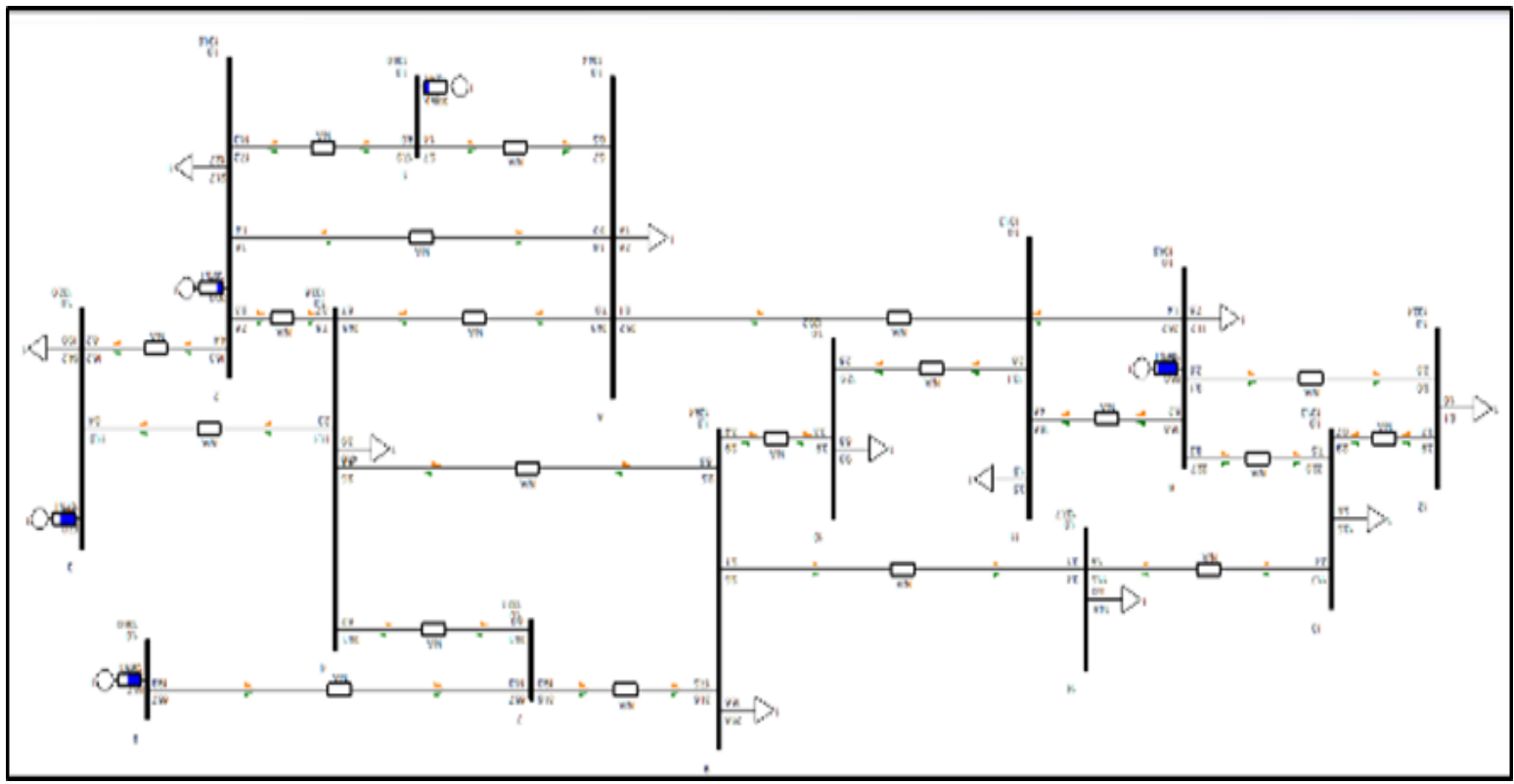

Figure 2. IEEE 14 bus system single line diagram 


\section{SIMULATION RESULT AND DISCUSSION}

\subsection{Weak area analysis for optimal solar PV placement}

For weak area analysis, the most vulnerable line can be detected using the VSI [23-25]. Determining the weak area in a network system is important in voltage stability analysis in order to determine the suitable placement of solar PV interconnection. VSI were used to detect the most sensitive bus and also critical line in a network system. The index values varies from 0 to 1 . With this index, the weakest line will show the index value that is closer to unity which is 1 .

The overall result for VSI are shown in Figure 3. From the graph in Figure 3, the results show that all the index values are below 1 which means there is no violation in term of line loading. Therefore, the network system has been verified to be stable and no voltage collapse in steady state mode. However, it can clearly be observed that all the VSI coincided and showed that the highest index reading at line 4-9. Therefore, as the conclusion, line branch 4-9 are the weakest line in the system. As in literature review based on [16], [17], [23], the optimal placement for solar PV in the network system is at the bus that located furthest from the generator buses and also high loading in order to provide better stability to the system. Hence, solar PV will be located at Bus 9.

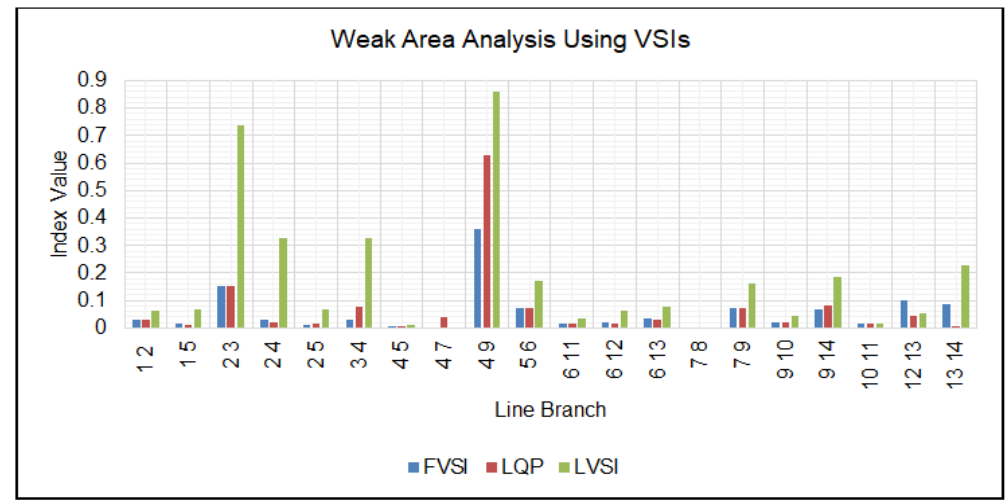

Figure 3. The value of each VSI for each branches

\subsection{Effect of the increment of solar PV integration}

Installation of solar PV into a network system will helps in increasing voltage profile and also reducing the VSI indices. But for some cases, when the PV penetration is higher and exceeding the load power demand, overloading can occurred at certain location in the system. Therefore, this research has proceeded to the next phase which is to test the ability of the network system to receive more power from the solar PV or in other words the maximum PV output power generation that will cause overloading or collapse issue to the system. For this test, the area of research has been narrowed down to the local area surrounding Bus 9 which mean the line branches that connected to the Bus 9 only which is shown in Figure 4.

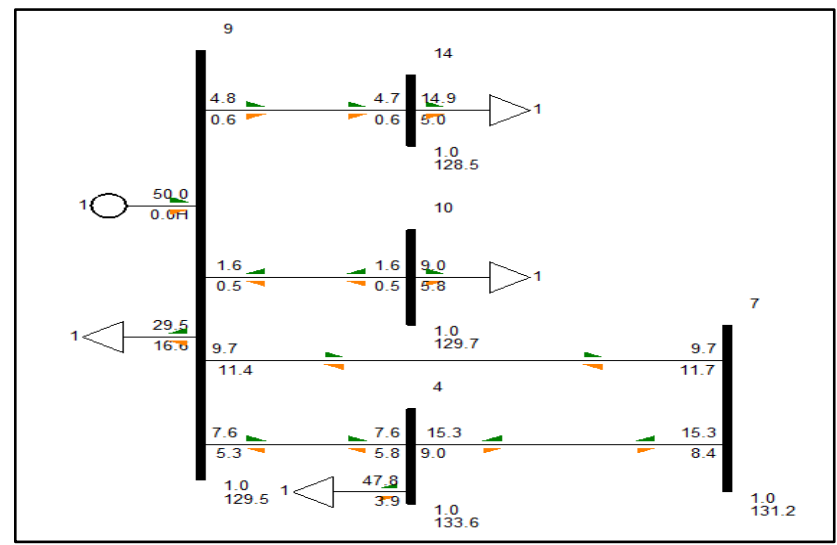

Figure 4. The line branches that connected to Bus 9 
Therefore, there are only 4 lines that connected to other 4 load buses. This is because, one of these lines will be the first that will be affected if there is overloading occurred that will result the voltage collapse to these marked buses. The output from solar PV started at value of $100 \mathrm{MW}$ and will have the increment of $100 \mathrm{MW}$ for every simulation test until the line branches overloaded. For every increment, the result for the bus voltage magnitude will be tabulate accordingly to observe the voltage profile as the PV output increases.

Based on Table 1, the network system is shifting from a stable system towards instability state which is when PV integration is at 300 MW capacity based on the selected bus voltages. The main reason behind this instability issue comes from the high increment of active power in the whole system. Most of the conventional generators have a control over their own terminal voltages and power output. The power generated by generator is divided into two types which is active power and reactive power. The generation of active power will require support from the reactive power. Active power is for supplying the load demand while reactive power provides the crucial function of regulating bus voltages [8-9].

Table 1. The voltage magnitude for each PV output increment

\begin{tabular}{ccccc}
\hline Bus & \multicolumn{4}{c}{ Voltage Magnitude (V) } \\
\cline { 2 - 5 } Number & No PV & $100 \mathrm{MW}$ & $200 \mathrm{MW}$ & $300 \mathrm{MW}$ \\
\hline 4 & 1.0122 & 1.0114 & 0.9999 & 0.3012 \\
7 & 1.0006 & 0.9918 & 0.9588 & 0.2441 \\
9 & 0.9803 & 0.9799 & 0.9461 & 0.1171 \\
10 & 0.9787 & 0.9813 & 0.9491 & 0.128 \\
14 & 0.9672 & 0.9728 & 0.9415 & 0.1242 \\
\hline
\end{tabular}

In addition, the injection of $300 \mathrm{MW}$ of PV output somehow blow out the whole system resulting a major power tripping. From the simulation result showed that the network system unstable because all the limits for the generators has been violated. The ratio of active power and reactive power is not well-balanced resulting the voltage collapse and line tripping. When reactive power is not sufficient, the voltage dropped drastically and there's no other possible way to deliver power for the load demand throughout the network system $[10,23]$.

The calculation of the VSI started with the initial steady state condition of network system which is without PV until the voltage got collapsed which is the PV output was at $300 \mathrm{MW}$. The voltage stability will be assessed to observe and further analyze the performance of the power system network with and without PV interconnection in terms of indices.

Based on all the formula for VSI stated earlier, the main factor that can manipulate the index values are the bus voltages. The bus voltages is on the denominator side of the formula meaning that voltage is inversely proportional to the index value. Based on Table 1, it can clearly be observed that as the PV injection increase, the bus voltages keep on decreasing. Therefore, when voltage collapse occurred which means $V s$ is very low, the numerator will be much higher than the denominator. At these conditions, the index will give an output value of more than 1 which indicates system instability.

From the earlier explanation regarding the correlation between reactive power and bus voltages, these index values were calculated as to strengthen the accuracy of the earlier theory. Based on the simulation result in Figure 5, at $300 \mathrm{MW}$ PV penetration, the network system become instable because most the generator buses operate at PF lower than 0.85 and having low voltage. Hence, this will cause very low voltage at the neighboring buses especially the load end. Based on the Figure 6, 7 and 8, at $300 \mathrm{MW}$, all the index values are showing similar results of reaching value 1 which indicates the line branches have become critical and voltage has already collapse. All the 3 graphs showing a similar pattern which are as the PV output increase, all the index values also keep increasing until the value exceed 1 .

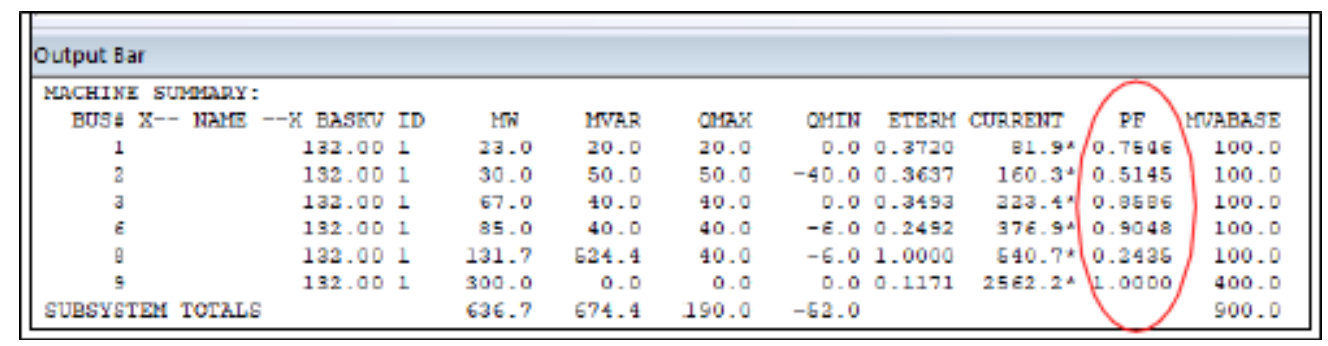

Figure 5. The result for $300 \mathrm{MW}$ of PV injection at Bus 9 


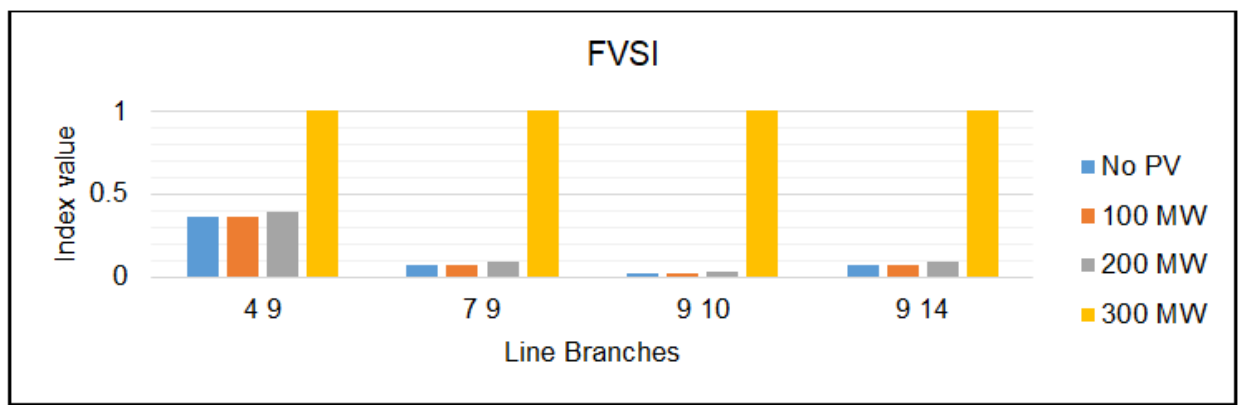

Figure 6. FVSI values for local area with and without PV

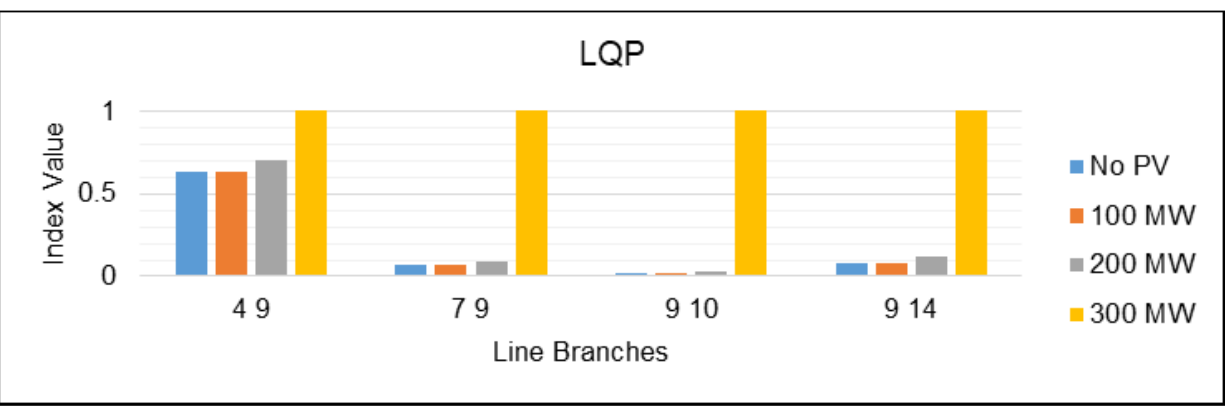

Figure 7. LQP values for local area with and without PV

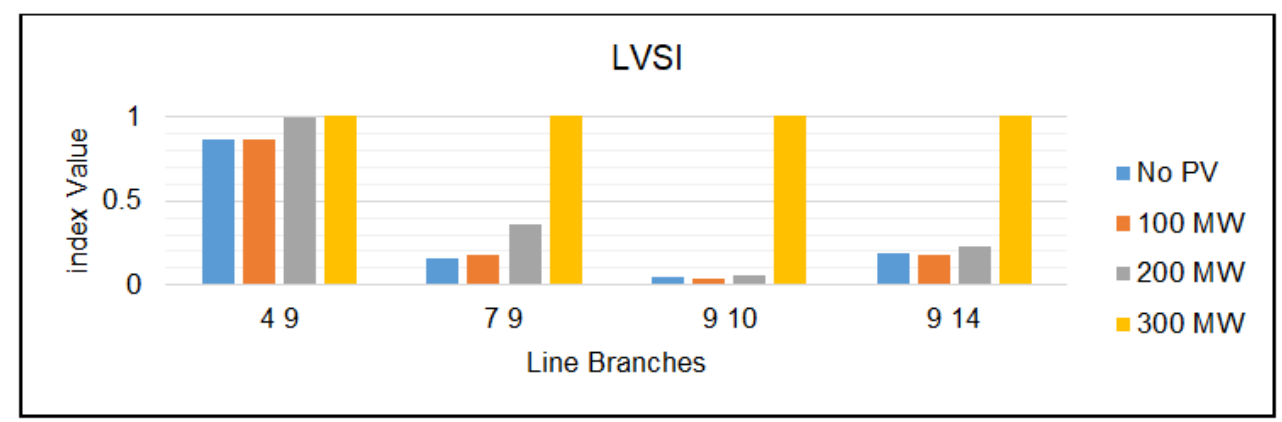

Figure 8. LVSI values for local area with and without PV

\section{CONCLUSION}

As for the conclusion, the calculation of the VSI are one of the early indicator of determining the stability state of the power system and very essential for the voltage stability analysis. The applicability of the proposed VSI has been investigated under several different situation and being compared with the actual simulation result. The application results clearly highlight the effectiveness and precision of the proposed VSI compared to the simulation result.

From all the results shown, it also can verify that the proposed methodology can be applied to determine optimal locations for solar PV in the transmission network. In addition, suitable placement of solar PV can lead to a better system stability.

However, when PV output increases, the total power generated by conventional generator will decreases accordingly depending on the nature of load. The generation of reactive power need to be increased in order to deliver all the active power to the end load. In addition, a network system is subjected to voltage collapse issues if there is heavy power flow into an area with insufficient reactive power reserves because of generators' limitation and optimal dispatch. Therefore, determining the weak area for line branches and buses at preliminary stage is crucial in order to maintain the power system stability and reliability. 


\section{ACKNOWLEDGEMENTS}

This research works are sponsored by the Ministry of Higher Education Malaysia under the Fundamental Research Grant 20160102FRGS.

\section{REFERENCES}

[1] B. Parida, S. Iniyan and R. Goic, "A review of solar photovoltaic technologies," Renewable and Sustainable Energy Reviews, vol. 15, no. 3, pp. 1625-1636, 2011

[2] P. Sampaio and M. González, "Photovoltaic solar energy: Conceptual framework," Renewable and Sustainable Energy Reviews, vol. 74, pp. 590-601, 2017.

[3] Y. He, Y. Pang, X. Li and M. Zhang, "Dynamic subsidy model of photovoltaic distributed generation in China," Renewable Energy, vol. 118, pp. 555-564, 2017.

[4] P. Luňáčková, J. Průša and K. Janda, "The merit order effect of Czech photovoltaic plants," Energy Policy, vol. 106, pp. 138-147, 2017.

[5] G. Năstase, A. Șerban, G. Dragomir, A. Brezeanu and I. Bucur, "Photovoltaic development in Romania. Reviewing what has been done," Renewable and Sustainable Energy Reviews, vol. 94, pp. 523-535, 2018

[6] A. Anzalchi and A. Sarwat, "Overview of technical specifications for grid-connected photovoltaic systems," Energy Conversion and Management, vol. 152, pp. 312-327, 2017.

[7] H. Saadat, Power system analysis, 4th ed. New York: The McGraw-Hill Companies, 2010.

[8] S. Eftekharnejad, V. Vittal, Heydt, B. Keel, and J. Loehr, "Impact of increased penetration of photovoltaic generation on power systems," IEEE Transactions on Power Systems, vol. 28, no. 2, pp. 893-901, 2013.

[9] M. Zainuddin, Sarjiya, T. P. Handayani, W. Sunanda, and F. E. P. Surusa, "Transient Stability Assessment of Large Scale Grid-Connected Photovoltaic on Transmission System," 2018 2nd International Conference on Green Energy and Applications (ICGEA), 2018.

[10] J. Parmar, "Importance of Reactive Power for System", Electrical Notes \& Articles, 2011. [Online]. Available: https://electricalnotes.wordpress.com/2011/03/21/importance-of-reactive-power-for-system/. [Accessed: 30 Dec 2018].

[11] N. R. Bujal, A. E. Hasan, and M. Sulaiman, "Analysis of voltage stability problems in power system," 2014 4th International Conference on Engineering Technology and Technopreneuship (ICE2T), 2014.

[12] P. Kundur, J. Paserba, V. Ajjarapu, G. Andersson, A. Bose, C. Canizares, N. Hatziargyriou, D. Hill, A. Stankovic, C. Taylor, T. van Cutsem, and V. Vittal, "Correction to 'Definition and Classification of Power System Stability," IEEE Transactions on Power Systems, vol. 19, no. 4, pp. 2124-2124, 2004.

[13] Y. Ma, S. Lv, X. Zhou, "Review Analysis of Voltage Stability in Power System," Proceeding of 2017 IEEE International Conference on Mechatronics and Automation, Aug. 2017.

[14] R. S. S. Reddy and T. G. Manohar, "Literature Review on Voltage stability phenomenon and Importance of FACTS Controllers In power system Environment," Global Journal of Researches in Engineering, vol. 12, no. 3, Mar. 2012.

[15] Tenaga Nasional Berhad, Electricity Supply Application Handbook, Kuala Lumpur, Malaysia: Distribution Division TNB , 2011

[16] A. W. H. Sie, I. Z. Abidin, and H. Hashim, "A methodology to determine suitable placement of solar photovoltaic sources in the transmission system taking into account voltage stability index (VSI) , 2014 IEEE International Conference on Power and Energy (PECon), 2014.

[17] M. H. Mansor, I. Musirin, and M. M. Othman, "Immune Log-Normal Evolutionary Programming (ILNEP) for solving economic dispatch problem with prohibited operating zones," 2017 4th Int. Conf. Ind. Eng. Appl. ICIEA 2017, no. 1, pp. 163-167, 2017.

[18] I. Musirin and T. Rahman, "On-line voltage stability based contingency ranking using fast voltage stability index (FVSI)," IEEE/PES Transmission and Distribution Conference and Exhibition, pp. 1118-1123.

[19] A. Mohamed and G. B. Jasmon, "A New Clustering Technique For Power System Voltage Stability Analysis," Electric Machines \& Power Systems, vol. 23, no. 4, pp. 389-403, 1995.

[20] S. Ratra, R. Tiwari, and K. Niazi, "Voltage stability assessment in power systems using line voltage stability index," Computers \& Electrical Engineering, 2018

[21] A. Kadam, M. R. Manjunath, and S. K. Bilgundi, "Optimal allocation of solar photovoltaic sources in $11 \mathrm{kV}$ system for loss reduction using stress test method," 2017 International Conference on Electrical, Electronics, Communication, Computer, and Optimization Techniques (ICEECCOT), 2017.

[22] J. Modarresi, E. Gholipour, and A. Khodabakhshian, "A comprehensive review of the voltage stability indices," Renewable and Sustainable Energy Reviews, vol. 63, pp. 1-12, 2016.

[23] H. Hashim, Y. R. Omar, I. Z. Abidin, R. A. Zahidi, N. Ahmad, and A. M. Ali, "Weak area analysis based on the apparent impedance and voltage indices," 2009 3rd International Conference on Energy and Environment (ICEE), 2009.

[24] C. Subramani, S. Dash, M. Bhaskar, M. Jagadeeshkumar, K. Sureshkumar, and R. Parthipan, "Line outage contingency screening and ranking for voltage stability assessment," 2009 International Conference on Power Systems, 2009.

[25] I. Musirin, T. Khawa, and A. Rahman, "Voltage stability based weak area clustering technique in power system," PECon 2004. Proceedings. National Power and Energy Conference, 2004. 